\title{
Nearctic freshwater tardigrades: a review
}

\author{
Mitchell M. McFATTER, Harry A. MEYER* and Juliana G. HINTON \\ Department of Biological and Environmental Sciences, McNeese State University, Lake Charles, Louisiana, U.S.A. 70609 \\ *e-mail corresponding author: hmeyer@mcneese.edu
}

\begin{abstract}
The distribution and ecology of limno-terrestrial Tardigrada in the Nearctic realm remain poorly known. This is especially true of freshwater tardigrades (i.e., species found in permanently submerged habitats), which have received much less attention than terrestrial species. We reviewed the literature on Nearctic freshwater tardigrades. Of 204 Nearctic limno-terrestrial tardigrade species, 44 have been collected from sediments and aquatic vegetation of streams, rivers, ponds, lakes, groundwater and cryoconite holes. Of these, 17 are hydrophilous species found exclusively or primarily in aquatic environments. Most of the remainder are probably washed in accidentally from terrestrial substrates. Among the hydrophilous species, five are endemic to the Nearctic realm and three cosmopolitan. Hypsibius dujardini is the most widely-distributed hydrophilous species. There are no regional collections of Nearctic freshwater tardigrades comparable to those for terrestrial species. Aquatic tardigrades are benthic, and are found in sediments and on aquatic vegetation. Hypsibius dujardini and other widespread species are found in both substrates, and there is thus no evidence of substrate specificity. Numerically, tardigrades usually comprise a minor component of benthic invertebrate communities. Nothing is known of their trophic relationships or dispersal in these habitats. The density of Nearctic freshwater tardigrade species peaks in the spring and/or fall. Future research should increase the spatial and temporal scale of study, and employ adequate replication.
\end{abstract}

Key words: limno-terrestrial, Tardigrada, substrate, freshwater

\section{INTRODUCTION}

The Nearctic biogeographical realm consists of the northern Mexican states, the continental United States of America, Alaska, Canada, and Greenland. The distribution and ecology of limno-terrestrial Tardigrada in this region remain poorly known. This is especially true of freshwater tardigrades (i.e., species found in more-orless permanently submerged habitats), which have received much less attention than terrestrial species. The tardigrades most likely to be found in permanent freshwater habitats are members of hydrophilous, i.e. distinctly aquatic, species. Other tardigrades sometimes found in aquatic habitats include the hygrophilous species characteristic of moist mosses and eurytopic species which tolerate a wide range of moisture conditions (Nelson \& Marley 2000).

This paper reviews the diversity and distribution of freshwater tardigrades in North America, the types of habitats in which they have been found, and their population ecology. We include only tardigrades that have been identified in the literature to a described species, i.e., we exclude collected tardigrades identified as "sp." and "cf." We accept authors' identifications at face value, unless modified in a subsequent publication. We base our taxonomy on Guidetti \& Bertolani (2005).

\section{DIVERSITY AND GEOGRAPHICAL DISTRIBUTION}

Relatively few papers have as their primary focus Nearctic freshwater tardigrades (Schuster et al. 1977;
Wainberg \& Hummon 1981; Kristensen 1982; Kathman \& Nelson 1987; Van Rompu et al. 1992; Strayer et al. 1994; Grøngaard et al. 1999; Nelson et al. 1999; Séméria 2003). Most other records of freshwater tardigrade distribution are from opportunistic samples taken during terrestrial surveys. While a number of regional collections of Nearctic terrestrial tardigrades have been published (Meyer \& Hinton 2007), such studies are lacking for freshwater tardigrades.

Of the 204 limno-terrestrial tardigrade species found in the Nearctic realm, 44 have been reported from freshwater (Tab. 1). Thulinius augusti has been widely reported, but there is a high possibility that many or all records of $T$. augusti (apart from type material) are actually of Pseudobiotus kathmanae (see Bertolani et al. 1999; Nelson et al. 1999).

The Nearctic freshwater tardigrade fauna shares more species in common with the Palearctic realm than any other biogeographical region (Tab. 1). Sixteen hydrophilous species have been collected only from aquatic habitats (Tab. 1). The hydrophilous tardigrade Hypsibius dujardini has been collected from moist mosses, but is primarily aquatic. Five hydrophilous species - Isohypsibius saltursus, Pseudobiotus kathmanae, Dactylobiotus grandipes, Dactylobiotus octavi, and Microhypsibius minimus - have not been reported outside North America (Tab. 1). Two aquatic species in the Nearctic realm - Dactylobiotus dispar, and Hypsbius dujardini - are cosmopolitan sensu Pilato \& Binda (2001), i.e., they have been found in five or more biogeographical realms (Tab. 1). 


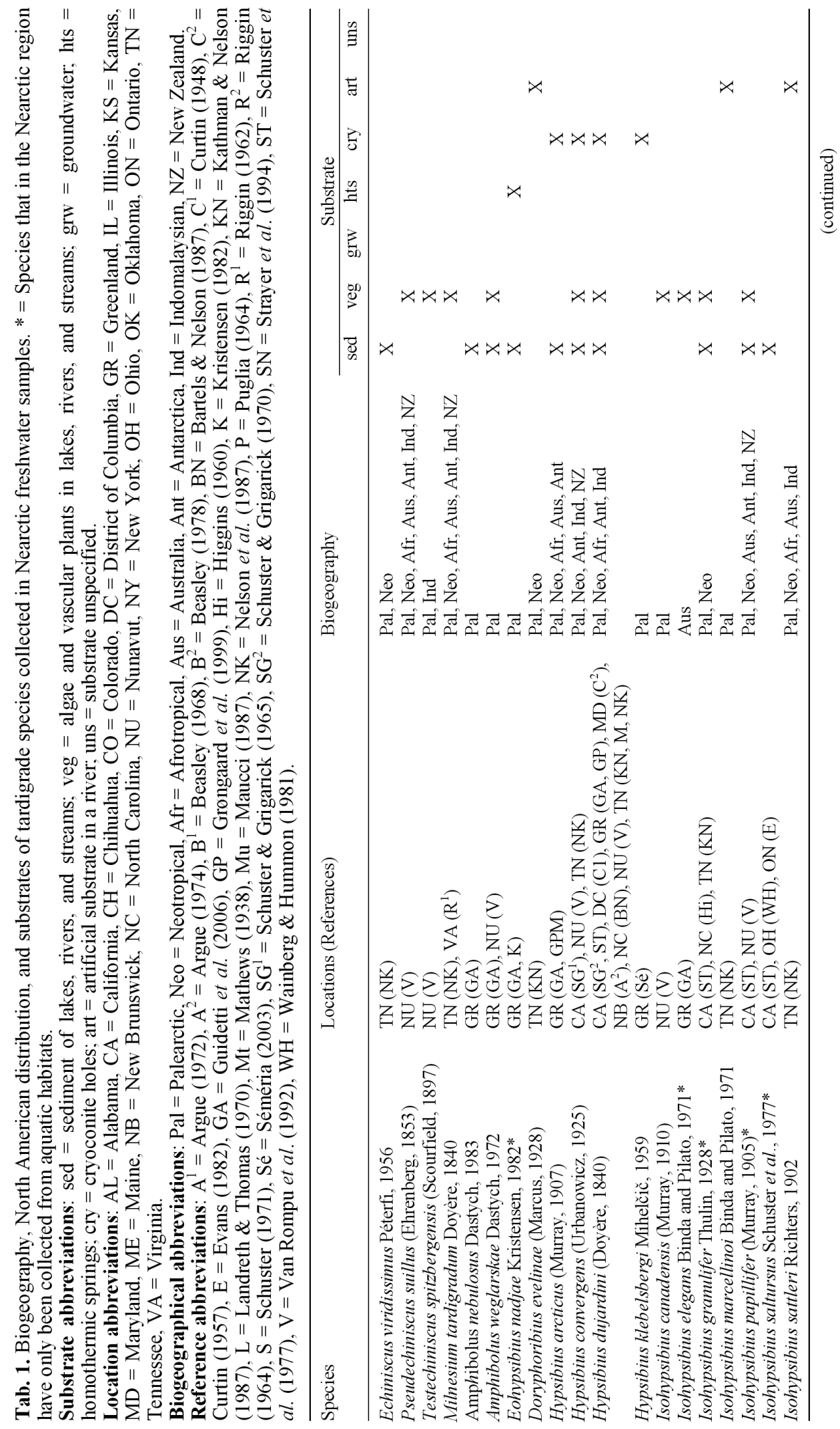




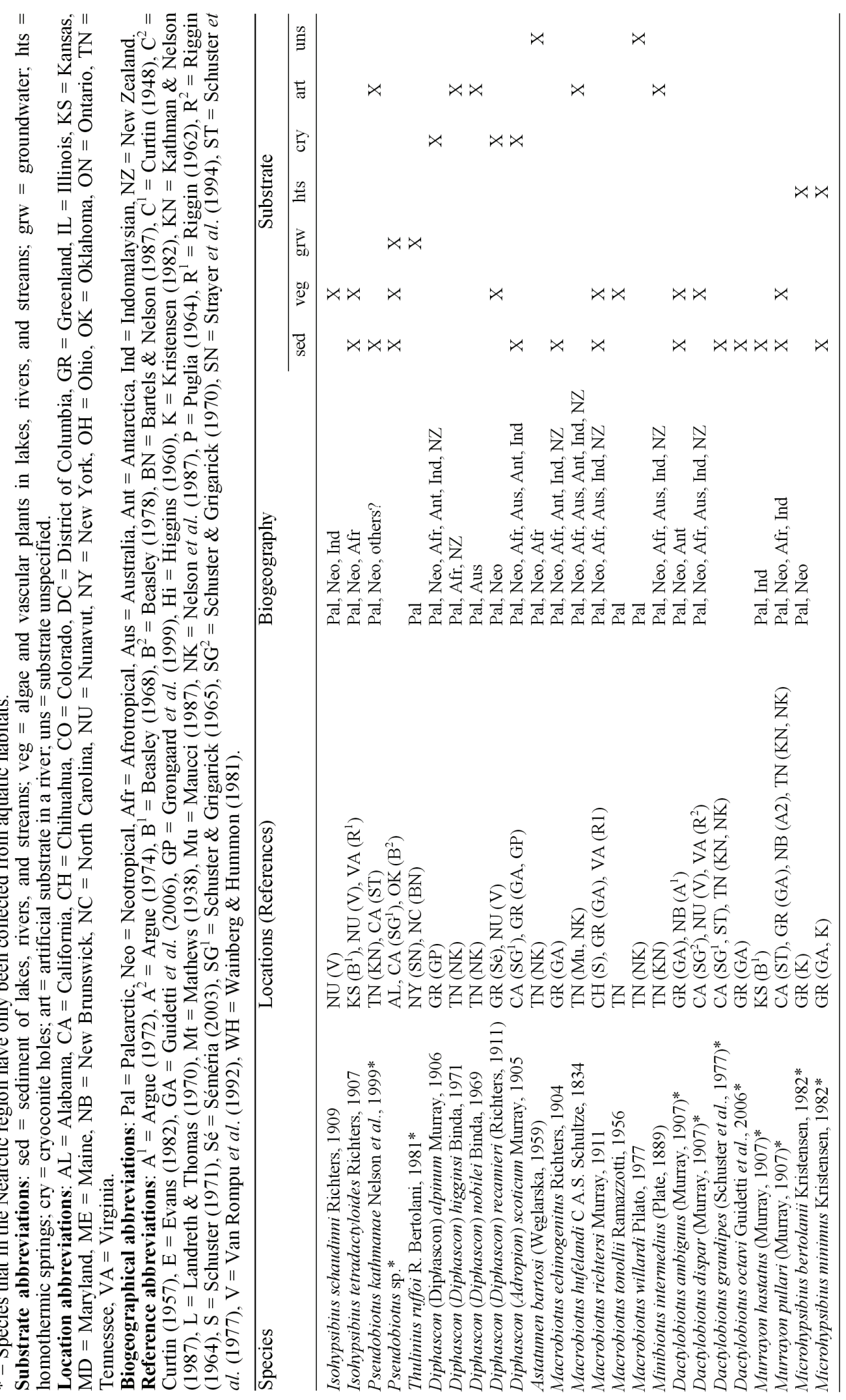


Three species - Milnesium tardigradum, Hypsibius convergens, and Macrobiotus hufelandi - are eurytopic species that sometimes inhabit freshwater habitats (Nelson \& Marley 2000). The remaining 23 species in table 1 are rarely found in freshwater, and most probably washed into streams or lakes from terrestrial substrates. Tardigrades can be blown into cryoconite environments from surrounding habitats, and move from hole to hole. Although Grøngaard et al. (1999) stated that tardigrades washed into the cryoconite holes of Greenland presumably perish when they eventually wash into the glacial drainage system, the many specimens found in Alpine cryoconite environments (Dastych \& Thaler 2002; Dastych et al. 2003) suggest that the possibility that these holes represent a more permanent tardigrade habitat needs further investigation.

Seven of the 17 hydrophilous tardigrade species are known in the Nearctic realm from only a single state or province (Tab. 1), sometimes from a single site. The known range of the other 10 species is much broader. The very limited data available suggest that the two species most likely to be encountered in a Nearctic freshwater sample are $H$. dujardini and Murrayon pullari (Tab. 1). How widespread P. kathmanae and $T$. augusti are in North America is an open question. Only further sampling, combined with rigorous standards of species identification, can resolve this issue.

The small-scale spatial distribution of terrestrial tardigrades has been shown to be very heterogeneous (Meyer 2006). Most likely the same is true for freshwater species: two studies (Puglia 1964; Schuster \& Grigarick 1965) reported tardigrades to be absent in some samples taken in freshwater habitats. A wider application of the sampling methodology and species accumulation curves employed in All Taxa Biological Inventories (see Bartels \& Nelson 2006) would improve our understanding of the species richness and distribution of Nearctic freshwater tardigrades.

Accurately assessing the diversity and distribution of Nearctic freshwater tardigrades would be facilitated if consistent standards of specific diagnosis were used (see Pilato \& Binda 2001; Guidetti \& Bertolani 2005). Many papers consulted in this survey were published before the development of such rigorous standards. For example, the "hufelandi group" was once considered one (or a few) cosmopolitan Macrobiotus species, but systematic revision (Biserov 1990a, b; Bertolani \& Rebecchi 1993) has shown that it includes a large number of noncosmopolitan species.

\section{ECOLOGY}

Nearctic tardigrades have been collected from groundwater, cryoconite holes, ponds and lakes, and streams and rivers. Cryoconite holes and groundwater have been the subject of only a few studies in North America (Kristensen 1982; Strayer et al. 1994; Grøngaard et al. 1999; Séméria 2003). Most records of
Nearctic freshwater tardigrades are from the aquatic vegetation (algae and vascular plants) of lentic and lotic habitats (Tab. 1). Some papers do not describe the freshwater habitats sampled, and some species have been collected only on artificial substrates.

Freshwater tardigrades are benthic animals, crawling on the surface of aquatic plants or algal mats, or in the interstices of sandy sediments (Nelson \& Marley 2000). Specimens have been found in plankton samples, but their presence in the water column probably results from benthic disturbance (Van Rompu et al. 1992). Although most Nearctic aquatic sampling has been done in shallow littoral waters, tardigrades have been collected from sublittoral benthic samples in Lakes Erie, Michigan, and Tahoe to depths of $23 \mathrm{~m}$ (Schuster et al. 1977; Evans 1982; Nalepa \& Quigley 1983). Tardigrades are usually a minor component of the sediment fauna (Nalepa \& Robertson 1981; Nalepa \& Quigley 1983), often representing less than $1 \%$ of the invertebrate fauna (Whitman \& Clark 1984; Strayer et al. 1994). Within sandy sediments, tardigrade abundance tends to increase with depth (Nalepa \& Robertson 1981; Whitman \& Clark 1984), and may dominate the meiofauna of deeper, reduced sediment (Nalepa \& Robertson 1981). The possibility that the component ratio of tardigrades in freshwater environments may vary with habitat (e.g., sediments $v s$ algal mats), or as a function of latitude or altitude, has not been investigated in North America.

The three most widely-distributed hydrophilous Nearctic species - $T$. augusti, $H$. dujardini, and Murrayon pullari - have been collected from both sediments and aquatic vegetation (Tab. 1). Available data do not suggest that hydrophilous tardigrades exhibit much substrate specificity. However, much more sampling is needed to confirm this hypothesis.

Few studies investigate the population dynamics of Nearctic freshwater tardigrades. Most of these encompass only a single year of sampling. Only Nelson et al. (1987) have revisited the same aquatic site after an interval of several years. Habitats studied, all from the continental United States, include streams and rivers (Landreth \& Thomas 1970; Wainberg \& Hummon 1981; Kathman \& Nelson 1987; Nelson et al. 1987), ponds and lakes (Landreth \& Thomas 1970; Schuster et al. 1977; Nalepa \& Quigley 1983), and groundwater (Strayer et al. 1994). Some Nearctic populations reach peak density in the fall (Schuster et al. 1977; Wainberg \& Hummon 1981), while others peak in the spring (Landreth \& Thomas 1970; Kathman \& Nelson 1987; Nelson et al. 1987; Strayer et al. 1994) or in both spring and fall (Nalepa \& Quigley 1983). Egg-laying may be year round (Kathman \& Nelson 1987) or limited to the season of peak abundance (Schuster et al. 1977; Strayer et al. 1994). Nelson et al. (1987) found the same seasonal pattern of abundance in a Tennessee stream in 1979-1980 and in 1983, although the relative abundance of the three dominant species was altered. Unpredictable 
environmental effects, such as severe droughts, can significantly impact tardigrade densities (Wainberg \& Hummon 1981), emphasizing the importance of sampling in multiple years before making inferences about seasonal periodicity.

\section{CONCLUSIONS}

The freshwater Tardigrada of the Nearctic realm have received much less attention than their terrestrial counterparts. Knowledge of their distribution and population dynamics is limited, and nothing is known about their dispersal and trophic relationships. Future research should increase both the temporal scale (i.e., multiple years) and spatial scale (i.e., collections from multiple sites within a region) of studies. More work is needed before we can understand how distribution and population dynamics in Nearctic freshwater tardigrades vary with habitat, altitude, and latitude. Given the high spatial heterogeneity typical of tardigrade distribution, estimates of abundance and species richness should be based on adequate replication (Kathman \& Nelson 1987; Meyer 2006).

\section{ACKNOWLEDGMENTS}

We gratefully acknowledgment the help provided by the Interlibrary Loan Department of McNeese State University. William Dees provided valuable comments on an earlier version of the manuscript.

\section{REFERENCES}

Argue, C.W. 1972. Tardigrades from New Brunswick, Canada. 2. Can. J. Zool., 50: 87-94.

Argue, C.W. 1974. Tardigrades from New Brunswick, Canada. 3. Can. J. Zool., 82: 919-922.

Bartels, P.J. \& D.R. Nelson. 2006. A large-scale, multihabitat inventory of the Phylum Tardigrada in the Great Smoky Mountains National Park, USA: A preliminary report. Hydrobiologia, 558: 111-118.

Beasley, C.W. 1968. Tardigrades from Kansas. Trans. Kans. Acad. Sci., 70: 464-470.

Beasley, C.W. 1978. The tardigrades of Oklahoma. Am. Midl. Nat., 99: 128-141.

Bertolani, R., N.J. Marley \& D.R. Nelson. 1999. Re-description of the genus Thulinia (Eutardigrada: Hypsibiidae) and of Thulinia augusti (Murray, 1907) comb. n. Zool Anz., 238: 139-145.

Bertolani, R. \& L. Rebecchi. 1993. A revision of the Macrobiotus hufelandi group (Tardigrada, Macrobiotidae) with some observations on the taxonomic characters of eutardigrades. Zool. Scripta, 22: 127-152.

Biserov, V.I. 1990a. On the revision of the genus Macrobiotus. The subgenus Macrobiotus s. str.: a new systematic status of the hufelandi group (Tardigrada, Macrobiotidae). Communication 1. Zool. Zh., 69: 5-17. (in Russian)

Biserov, V.I. 1990b. On the revision of the genus Macrobiotus. The subgenus Macrobiotus s. str.: a new systematic status of the hufelandi group (Tardigrada, Macrobiotidae). Communication 2.1. Zool. Zh., 69: 38-50. (in Russian)

Curtin, C.B. 1948. The tardigrade fauna of the District of Columbia. J. Wash. Acad. Sci., 38: 251-254.

Curtin, C.B. 1957. Studies on the tardigrades. II. Some tardigrades from Maryland. P. Acad. Sci. Publ., 31: 142-146.
Dastych, H., H. Kraus \& K. Thaler. 2003. Redescription and notes on the biology of the glacier tardigrade Hypsibius klebelsbergi Mihelčič, 1959 (Tardigrada), based on material from the Ötztal Alps, Austria. Mitt. hamb. zool. Mus. Inst., 100: 73-100.

Dastych, H. \& K. Thaler. 2002. The tardigrade Hebesuncus conjungens (Thulin, 1911) in the Alps, with notes on morphology and distribution (Tardigrada). Entomol. Mitt. Zool. Mus. Hamb., 14: 83-94.

Evans, W.A. 1982. Abundances of micrometazoans in three sandy beaches in the island area of western Lake Erie. Ohio J. Sci., 82: 246-251.

Grøngaard, A., P.J.A. Pugh \& S. McInnes. 1999. Tardigrades, and other cryoconite biota, on the Greenland ice sheet. Zool. Anz., 238: 211-214.

Guidetti, R., T. Altiero \& J.G. Hansen. 2006. A new species of freshwater tardigrades from Disko Island (Greenland) increases an unsolved paradox in tardigrade systematics. Hydrobiologia, 558: 69-79.

Guidetti, R. \& R. Bertolani. 2005. Tardigrade taxonomy: an updated check list of the taxa and a list of characters for their identification. Zootaxa, 845: 1-46.

Higgins, R.P. 1960. Some tardigrades from the Piedmont of North Carolina. J. Elisha Mitchell Sci. Soc., 76: 29-35.

Kathman, R.D. \& D.R. Nelson. 1987. Population trends in the aquatic tardigrade Pseudobiotus augusti (Murray). In: R. Bertolani (Ed.), Biology of Tardigrades. Selected Symposia and Monographs U.Z.I., 1. Mucchi Editore, Modena, Italy: 158-168.

Kristensen, R.M. 1982. New aberrant eutardigrades from homothermic springs on Disko Island, West Greenland. In: D. Nelson (Ed.), Proceedings of the Third International Symposium on the Tardigrada. East Tennessee State University Press, Johnson City, Tennessee: 203-220.

Landreth, Jr., K. \& B.O. Thomas. 1970. Studies of the egg laying process in Tardigrada (Hypsibius [Isohypsibius] augusti) in Weld County. J. Col.-Wyo. Acad. Sci., 7: 9.

Mathews, G.B. 1938. Tardigrada from North America. Am. Midl. Nat., 19: 619-627.

Maucci, W. 1987. A contribution to the knowledge of the North American Tardigrada with emphasis on the fauna of Yellowstone National Park (Wyoming). In: R. Bertolani, (Ed.), Biology of Tardigrades. Selected Symposia and Monographs U.Z.I. 1. Mucchi Editore, Modena, Italy: 187-210.

Meyer, H.A. 2006. Small-scale spatial distribution variability in terrestrial tardigrade populations. Hydrobiologia, 558: 133-139.

Meyer, H.A. \& J. Hinton. 2007. Limno-terrestrial Tardigrada of the Nearctic Realm. In: G. Pilato \& L. Rebecchi (Eds), Proceedings of the Tenth International Symposium on Tardigrada. J. Limnol., 66(Suppl. 1): 97-103.

Nalepa, T.F. \& M.A. Quigley. 1983. Abundance and biomass of the meiobenthos in nearshore Lake Michigan with comparisons to the macrobenthos. J. Great Lakes Res., 9: 530-547.

Nalepa, T.F. \& A. Robertson. 1981. Vertical distribution of the zoobenthos in southeastern Lake Michigan with evidence of seasonal variation. Freshw. Biol., 11: 87-96.

Nelson, D.R., C.J. Kincer \& T.C. Williams. 1987. Effects of habitat disturbances on aquatic tardigrade populations. In R. Bertolani (Ed.), Biology of Tardigrades. Selected Symposia and Monographs U.Z.I., 1. Mucchi Editore, Modena, Italy: 141-153.

Nelson, D.R. \& N.J. Marley. 2000. The biology and ecology of lotic Tardigrada. Freshw. Biol., 44: 93-108.

Nelson, D.R., N.J. Marley \& R. Bertolani. 1999, Re-description of the genus Pseudobiotus (Eutardigrada, Hypsibiidae) and of the new type species Pseudobiotus kathmanae sp. n. Zool. Anz., 238: 311-317. 
Pilato, G. \& M.G. Binda. 2001. Biogeography and limno-terrestrial tardigrades: Are they truly incompatible binomials? Zool. Anz., 240: 511-516.

Puglia, C.H. 1964. Some tardigrades from Illinois. Trans. Am. Microsc. Soc., 83: 300-311.

Riggin, Jr., G.T. 1962. The Tardigrada of southwest Virginia: With the addition of a description of a new marine species from Florida. Virginia Agric. Exp. Stn, Tech. Bull., 152: 1145.

Riggin, Jr., G.T. 1964. Tardigrades from the southern Appalachian Mountains. Trans. Am. Microsc. Soc., 83: 277-282.

Schuster, R.O. 1971. Tardigrada from the Barranca del Cobre, Sinaloa and Chihuahua, Mexico. Proc. Biol. Soc. Wash., 84: 213-224.

Schuster, R.O. \& A.A. Grigarick. 1965. Tardigrada from western North America with emphasis on the fauna of California. Univ. Cal. Publ. Zool., 76: 1-67.

Schuster, R.O. \& A.A. Grigarick. 1970. Tardigrada of Santa Cruz Island, California. Pan-Pac. Entomol., 46: 184-193.
Schuster, R.O., E.C. Toftner \& A.A. Grigarick. 1977. Tardigrada of Pope Beach, Lake Tahoe, California. Wasmann J. Biol., 35: 115-136.

Séméria, Y. 2003. Tardigrades des cryoconites du Groenland. Exploration de l'inlandsis et de ses abords immédats. Bull. mens. Soc. linn. Lyon, 73: 191-192.

Strayer, D., D.R. Nelson \& E.B. O’Donnell. 1994. Tardigrades from shallow groundwaters in southeastern New York, with the first record of Thulinia from North America. Trans. Am. Microsc. Soc., 113: 325-332.

Van Rompu, E.A., W.H. De Smet \& L. Beyens. 1992. Contributions to the Tardigrada of the Canadian High-Arctic 1. Freshwater tardigrades from Devon Island, Northwest Territories. Can. Field-Nat., 106:303-310.

Wainberg, R.H. \& W.D. Hummon. 1981. Morphological variation of the tardigrade Isohypsibius saltursus. Trans. Am. Microsc. Soc., 100: 21-33.

Whitman, R.L. \& W.J. Clark. 1984. Ecological studies of the sand-dwelling community of an East Texas stream. Freshw. Invertebr. Biol., 3: 59-79. 